\title{
Esophagus and Esophagogastric Junction Cancer pT1a TNM Finding v8
}

National Cancer Institute

\section{Source}

National Cancer Institute. Esophagus and Esophagogastric Junction Cancer pT 1a TNM

Finding v8. NCI Thesaurus. Code C133378.

Esophagus and esophagogastric junction cancer with tumor invading the lamina propria or muscularis mucosae. (from AJCC 8th Ed.) 